\title{
Redescription of Spinitectus tabascoensis (Nematoda: Cystidicolidae) from fishes of the Lacandon rain forest in Chiapas, southern Mexico, with remarks on Spinitectus macrospinosus and $S$. osorioi
}

\author{
František Moravec $^{1}$, Guillermo Salgado-Maldonado ${ }^{2}$, Juan M. Caspeta-Mandujano ${ }^{3}$ and David González-Solís ${ }^{4}$ \\ ${ }^{1}$ Institute of Parasitology, Biology Centre of the Academy of Sciences of the Czech Republic, Branišovská 31, 37005 České \\ Budějovice, Czech Republic; \\ ${ }_{2}^{2}$ Instituto de Biología, Universidad Nacional Autónoma de México, A.P. 70-153, C.P. 04510, México, D.F., Mexico; \\ ${ }^{3}$ Laboratorio de Parasitología de Animales Silvestres, Facultad de Ciencias Biológicas y Centro de Investigaciones Biológicas, \\ Universidad Autónoma del Estado de Morelos, Av. Universidad No. 1001, Col. Chamilpa, C.P. 62210, Cuernavaca, Morelos, \\ Mexico; \\ ${ }^{4}$ Parasitología del Necton, El Colegio de la Frontera Sur (ECOSUR), Unidad Chetumal, Avenida Centenario Km. 5.5, A.P. 424, \\ C.P. 77900, Chetumal, Quintana Roo, Mexico
}

\begin{abstract}
Two little-known species of Spinitectus (Nematoda: Cystidicolidae) were, for the first time, recorded from fishes of the Lacantún River (Usumacinta River basin) in the Lacandon rain forest, Chiapas, southern Mexico: S. tabascoensis Moravec, García-Magaña et Salgado-Maldonado, 2002 in intestines of Ictalurus furcatus (Valenciennes) (Ictaluridae) (adults and juveniles), Cathorops aguadulce (Meek) and Potamarius nelsoni (Evermann et Goldsborough) (both Ariidae) (in both only juveniles), and S. osorioi Choudhury et Pérez-Ponce de León, 2001 in Atherinella alvarezi (Díaz-Pardo) (Atherinopsidae) (adults in intestine) and Eugerres mexicanus (Steindachner) (Gerreidae) (adults and juveniles in stomach). Eugerres mexicanus, C. aguadulce and P. nelsoni represent new host records. Detailed light and electron microscopical studies of $S$. tabascoensis revealed some taxonomically important, previously not observed features, such as cuticular spines arranged in four sectors, the cephalic structure, the number (2) of ventral precloacal ridges or the structure of the male caudal end. Therefore, Spinitectus tabascoensis is redescribed. Spinitectus macrospinosus Choudhury et Perryman, 2003, described from ictalurids in Canada and the USA, is considered its junior synonym. Spinitectus tabascoensis seems to be a specific parasite of Ictalurus spp., whereas C. aguadulce and P. nelsoni, as well as some other fishes, serve only as its paratenic hosts. The definitive hosts of $S$. osorioi are atherinopsid fish (A. alvarezi, Chirostoma spp.), whereas the gerreid E. mexicanus probably serves only as its postcyclic host.
\end{abstract}

Key words: parasitic nematode, Spinitectus, fish, Atherinella, Cathorops, Eugerres, Ictalurus, Potamarius, Lacandon rain forest, Lacantún River, Chiapas, Mexico

The genus Spinitectus Fourment, 1884 includes a large number of species described mainly from freshwater and marine fishes (Moravec et al. 2002). To date, 11 of them have been recorded from North American fishes, including the 6 reported from Mexico (Choudhury and Perryman 2003, Caspeta-Mandujano 2005, Caspeta-Mandujano et al. 2007). However, the morphology of some of them remains insufficiently known, which complicates the species identification.

During studies on the helminth fauna of fishes of the Lacantún River (Usumacinta River basin) in the famous Lacandon rain forest, Chiapas, southern Mexico, carried out in 2004 and 2007, two little-known species of Spinitectus were recorded. Results of their detailed examina- tion by both light and electron microscopy are presented below.

\section{MATERIALS AND METHODS}

Fish were collected by using a gill net from the Lacantún River (stations Chajul - 16 $06^{\prime} 03^{\prime \prime} \mathrm{N}, 90^{\circ} 57^{\prime} 30^{\prime \prime} \mathrm{W}$ and El Remolino $\left.16^{\circ} 14^{\prime} 19^{\prime \prime} \mathrm{N}, 90^{\circ} 51^{\prime} 00^{\prime \prime} \mathrm{W}\right)$, Usumacinta River drainage system, Chiapas, southern Mexico in December 2004 and November 2007. Nematodes recovered from the digestive tract were fixed in hot $4 \%$ formaldehyde solution. For light microscopical (LM) examination, they were cleared with glycerine. Drawings were made with the aid of a Zeiss microscope drawing attachment. Specimens used for scanning electron microscopy (SEM) were postfixed in $1 \%$ osmium tetroxide, dehydrated through a graded acetone series, critical point dried and sputter-coated with pla- 
tinum; they were examined using a JEOL JSM-7401F scanning electron microscope at an accelerating voltage of $4 \mathrm{kV}$ GB low. All measurements are in micrometres unless otherwise stated. Fish names follow FishBase (Froese and Pauly 2009).

\section{RESULTS}

Spinitectus tabascoensis Moravec, García-Magaña et Salgado-Maldonado, 2002 Figs. 1, 2

Syn.: Spinitectus macrospinosus Choudhury et Perryman, 2003.

Description (based on adult specimens from I. furcatus): Whitish, slender, medium-sized nematodes. Cephalic end rounded, posterior end conical. Surface of body with transverse rings of markedly long, posteriorly oriented conical teeth; rings interrupted at both sides of body, as well as dorsally and ventrally, forming thus four sectors (Figs. 1A, 2F). First ring situated short distance anterior to end of vestibule, 2nd ring approximately at its level; 1 st and 2nd rings not markedly close to each other; no rings of spines raised. Largest spines present in region of excretory pore, anterior spines somewhat smaller; spines gradually diminishing in size posteriorly from about level of excretory pore towards end of glandular oesophagus. First ring formed by 18-22 spines (Figs. 1A, 2F). Spination of body visible under light microscope ends in both sexes posterior to end of glandular oesophagus. Oral aperture oval, dorsoventrally elongated. Two welldeveloped pseudolabia with not dorsoventrally expanded internal parts present (Figs. 1B, 2E, F); each pseudolabium bearing small, anteriorly protruding protuberance (Fig. 2E, G). Four submedian sublabia well developed, narrow; dorso-lateral sublabia, as well as ventro-lateral sublabia, connecting to each other dorsally and ventrally. Four small submedian cephalic papillae and pair of lateral amphids present (Figs. 1B, 2E, G). Vestibule long, thinwalled, with anterior end distinctly distended to form funnel-shaped prostom in lateral view. Oesophagus clearly divided into anterior muscular portion and much longer and slightly wider posterior glandular portion. Nerve ring encircles muscular oesophagus near its anterior end, approximately at level of 4 th ring of cuticular spines. Excretory pore situated between 6 th and 7 th rings of spines. Small, finger-shaped deirids situated just anterior to 2 nd ring of spines. Tail of both sexes conical.

Male (5 specimens): Length of body 9.49-11.98 mm, maximum width 95-136. First cuticular ring 111-141 from anterior extremity, being formed by 18-20 spines 12-15 long. Maximum length of spines 27-30. Vestibule including prostom 135-156 long; prostom 15 long and 24-27 wide. Muscular oesophagus 495-600 long, 18-21 wide; glandular oesophagus 2.04-2.99 mm long, 42-60 wide; length ratio of both parts of oesophagus 1:4-5. Entire oesophagus and vestibule representing $25-34 \%$ of whole body length. Nerve ring and excretory pore 180
A

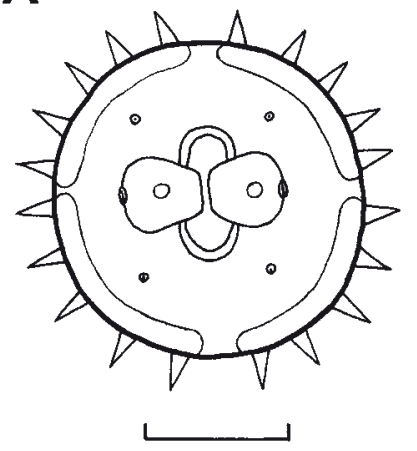

B

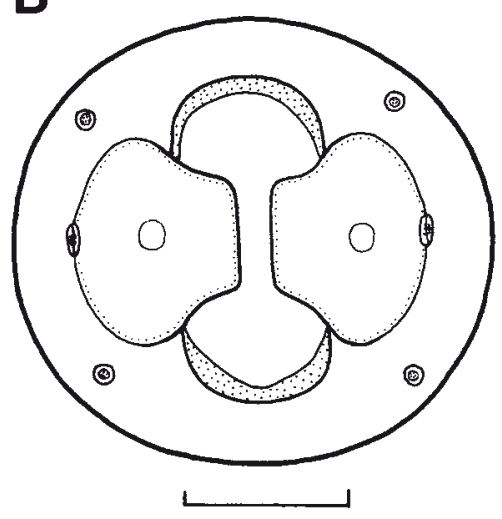

Fig. 1. Spinitectus tabascoensis Moravec, García-Magaña et Salgado-Maldonado, 2002. A - cephalic end, apical view; B - mouth, apical view. Scale bars: $A=20 \mu \mathrm{m} ; \mathrm{B}=10 \mu \mathrm{m}$.

240 and 288-387, respectively, from anterior extremity. Deirids 126-165 from anterior end. Posterior end of body ventrally curved, provided with well-developed caudal alae reaching posteriorly end of tail. Two well-developed, longitudinal cuticular ridges (area rugosa) present in precloacal region. Preanal papillae: 4 pairs of subventral pedunculate, equally distributed papillae preset. Postanal papillae: 5 pairs of subventral pedunculate papillae and 1 pair of ventral sessile papillae situated at level of last pair of subventrals; pair of small phasmids located just posterior to papillae (Fig. 2H); 2nd and 3rd pairs of papillae, and last two pairs of papillae and phasmids close together. Large (left) spicule 210-240 long; length of its shaft $93-108$ (39-46\% of entire spicule). Small (right) spicule boat-shaped, 72-81 long, with narrowed, somewhat ventrally bent distal end. Length ratio of spicules 1:2.80-3.20. Tail 165-252 long, with bluntly pointed tip.

Female (5 specimens with mature eggs; measurement of 3 specimens with immature eggs in parentheses): Body length 14.39-15.74 (11.11-12.46) mm, maximum width 136-163 (136-150). First cuticular ring 132-162 (120-126) from anterior extremity, being formed by 


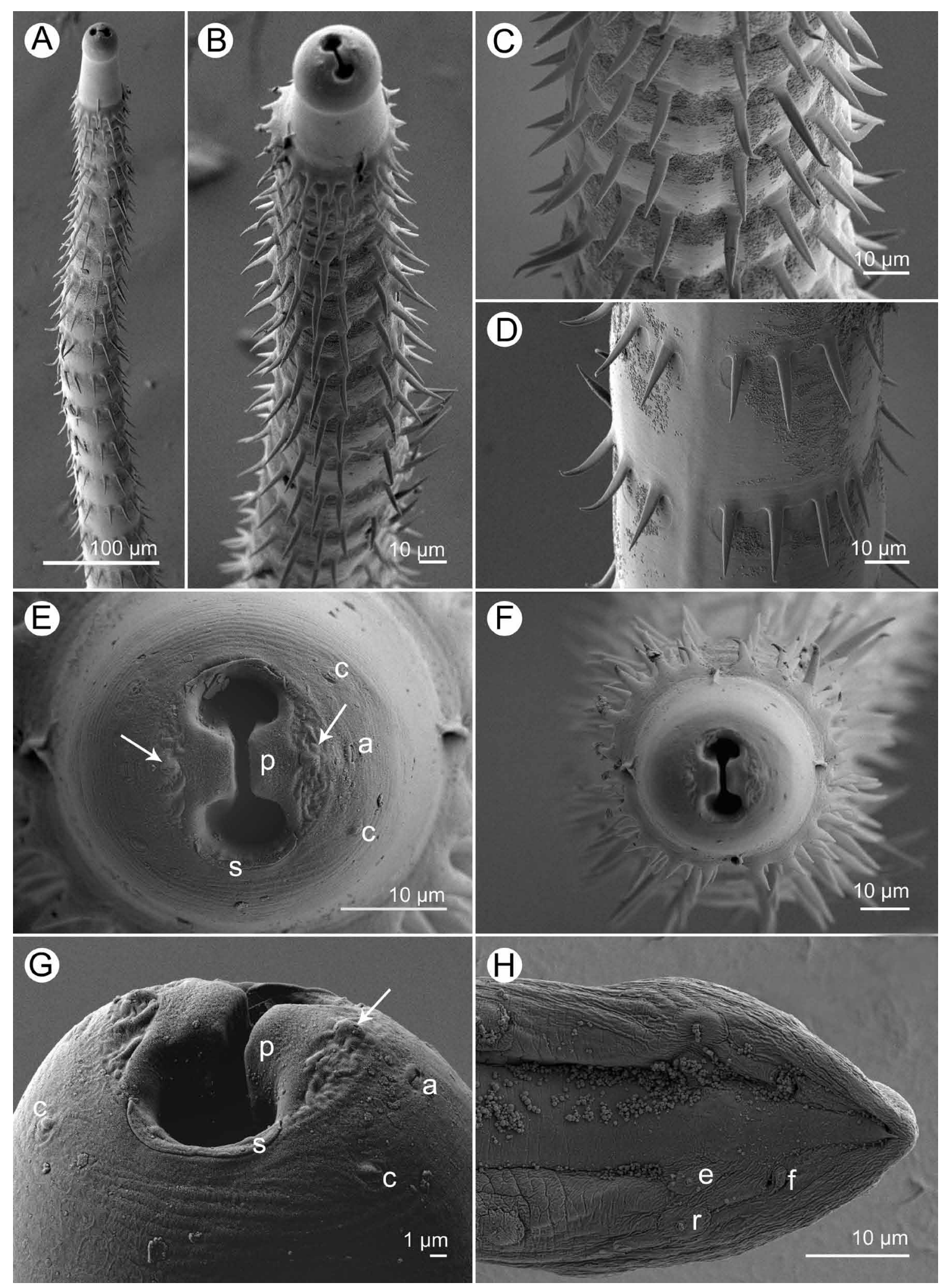

Fig. 2. Spinitectus tabascoensis Moravec, García-Magaña et Salgado-Maldonado, 2002, scanning electron micrographs. A - anterior part of body, lateral view; B - anterior end of body, subdorsal view; $\mathbf{C}$ - spines on anterior part of body, lateral view (note lateral line without spines in middle); $\mathbf{D}$ - more posterior spines, dorsal view (note dorsal line without spines); $\mathbf{E}$ - cephalic end, apical view (arrows indicate small anterior pseudolabial projections); $\mathbf{F}$ - anterior end, apical view (focused to first ring of spines); $\mathbf{G}$-cephalic end, dorsoventral view (arrow indicates small anterior pseudolabial projection); $\mathbf{H}$ - end of male tail, ventral view. Abbreviations: $\mathrm{a}$ - amphid; $\mathrm{c}$ - submedian cephalic papilla; $\mathrm{e}$ - ventral postanal papilla; $\mathrm{f}$ - phasmid; $\mathrm{p}$ - pseudolabium; $\mathrm{r}$ - postanal papilla of last (5th) subventral pair; s - sublabium. 
20-22 spines 12-15 (15) long. Maximum length of cuticular spines 30-33 (27-30). Vestibule including prostom 159-180 (141-144) long; prostom 15 (15) long and 2730 (27-30) wide. Muscular oesophagus 531-660 (423483) long, 18-24 (18-24) wide; glandular oesophagus 2.51-2.93 (2.64-2.66) long, 48-57 (60-66) wide; length ratio of both parts of oesophagus 1:4-5 (1:6). Nerve ring and excretory pore 240-255 (201-216) and 330-390 (297-330), respectively, from anterior extremity. Deirids 150-186 (135-144) from anterior end. Vulva not elevated, postequatorial, situated 7.86-8.46 (6.66-7.18) from posterior extremity (at 54-59 (58-60)\% of body length). Vagina muscular, directed posteriorly from vulva. Eggs in uterus oval, thick-walled, smooth; size of larvated eggs $39-45 \times 21-27(-)$; thickness of their wall $3(-)$. Tail conical, 192-210 (165-192) long, with small knob-like appendage at tip.

H o s t s : Blue catfish, Ictalurus furcatus (Valenciennes) (Ictaluridae, Siluriformes) (body length 24-48 cm). Juveniles also in estuarine sea catfish, Cathorops aguadulce (Meek) (body length 23-26 cm), and Lacandon sea catfish, Potamarius nelsoni (Evermann et Goldsborough) (both Ariidae, Siluriformes) (body length $25 \mathrm{~cm}$ ). Previously also reported (as S. macrospinosus) from channel catfish, Ictalurus punctatus (Rafinesque) (partly reported as I. lacustris), and juveniles and immature specimens from stonecat, Noturus flavus Rafinesque (Ictaluridae), and goldeye, Hiodon alosoides (Rafinesque) (Hiodontidae, Osteoglossiformes) (see Choudhury and Perryman 2003).

Site of infection: Intestine.

L o c a lity: Lacantún River (Usumacinta R. basin), Chiapas, southern Mexico (collected in December 2004 and November 2007). Originally described from I. furcatus from upper reaches of the Usumacinta River, Tabasco, southern Mexico (Moravec et al. 2002). Later reported (as S. macrospinosus) from Ictalurus furcatus and I. punctatus from southern Manitoba, Canada, and Kentucky-Tennessee and Oklahoma, eastern and central USA (Choudhury and Perryman 2003).

Prevalence and intensity: I. furcatus: $92 \%$ (11 fish infected/12 fish examined); 1-39 (mean 11) nematodes per fish. C. aguadulce: 16\% (3/19); 1-6 (mean 3). P. nelsoni: $1 / 3 ; 6$.

Deposition of voucher specimens: Helminthological Collection of the Instituto de Biología, UNAM, Mexico City (Cat. No. 6889); Helminthological Collection of the Institute of Parasitology, Biology Centre of the ASCR (Cat. No. N-927).

Comments. Moravec et al. (2002) described Spinitectus tabascoensis from only two available mature specimens ( 1 male and 1 female) and, consequently, these could not be examined by SEM. However, some taxonomically important morphological features of cystidicolids, such as the cephalic structure, arrangement and numbers of cuticular spines or details of the male caudal end, can be properly studied only by using the SEM (e.g., Jilek and Crites 1982, Ko 1986, Moravec 1996, 2007, CaspetaMandujano et al. 2007, Moravec and Klimpel 2007).

Specimens of $S$. tabascoensis for the present study were obtained from the type host (Ictalurus furcatus) from the same water drainage system from where this nematode was described, so that there are no doubts that they belong to this species. In contrast to the original description, it was possible to find a considerable biometrical range of mature specimens, which may be distinctly larger than originally described. Fully mature (larvated) eggs of this species are described for the first time. The examination by SEM revealed the true detailed structure of the cephalic end, arrangement and numbers of cuticular spines, presence of deirids, number of ventral precloacal cuticular ridges, and the arrangement of posteriormost caudal papillae and phasmids. In contrast to the original description, the cuticular rings of spines were found to be separated not only laterally, but also dorsally and ventrally, forming thus four distinct sectors. The actual number of spines in the first ring is 18-22 instead of 16-18 as erroneously given previously. There are not four, but only two longitudinal ventral precloacal ridges. Deirids were not described in the original description.

Choudhury and Perryman (2003) established a new species, Spinitectus macrospinosus, based on specimens found in the intestine of the channel catfish Ictalurus punctatus in southern Manitoba, Canada. They also reexamined the specimens reported by Hoffnagle et al. (1990) as Spinitectus gracilis in I. furcatus from Kentucky Lake (Tennessee River basin), USA and they found them to be, in fact, S. macrospinosus. They also assigned to this species an immature specimen of Spinitectus from I. lacustris (= syn. of I. punctatus) from Lake Texoma (Mississippi River basin), Oklahoma. In the same Canadian locality from where adults of S. macrospinosus were described in I. punctatus, Choudhury and Perryman (2003) recorded conspecific juveniles and immature worms from the stonecat Noturus flavus and the goldeye Hiodon alosoides (Rafinesque), indicating that the nematode is unable to mature in these hosts. They also mentioned that the records from the United States would seem to suggest that $S$. macrospinosus is in fact widely distributed in North America, being thus possibly "another species with a range approaching that of its host clade, Ictalurus".

Mainly in possessing markedly long cuticular spines, S. macrospinosus differs from all other North American species of Spinitectus (see Choudhury and Perryman 2003), except for $S$. tabascoensis parasitizing a congeneric host in southern Mexico. The morphology of both species is very similar and $S$. tabascoensis was distinguished from S. macrospinosus by "having only two sectors of spines per row, the lack of the distinctive reduction of spine number per sector, the lack of a terminal ventral barb on the short spicule, and by having the last three pairs of postanal papillae clustered together". 
However, the present study of $S$. tabascoensis by SEM shows that some features given in the original description were inaccurate and that the distribution of cuticular spines and the cephalic structure are identical with those in S. macrospinosus. Small anterior pseudolabial protrusions found by SEM in $S$. tabascoensis in the present study were not mentioned in the original description of S. macrospinosus, but they are distinctly visible on the scanning electron images (figs. 3 and 4) in the publication of Choudhury and Perryman (2003). Regarding the reported "recurved ventral barb" on the small spicule of $S$. macrospinosus: it is apparently not a barb, but slightly more sclerotized distal parts of expanded wing-like sides of the small spicule visible in lateral view, which are typical of many cystidicolids; the shape of this spicule may considerably vary depending on the spicule position inside the nematode body. The distribution of posteriormost pairs of caudal papillae was not studied in detail by SEM by Choudhury and Perryman (2003); they studied these papillae only using LM in lateral view. As confirmed by the present SEM study, the seventh pair of postanal "papillae" reported by Moravec et al. (2002) is in fact represented by phasmids (not observed by Choudhury and Perryman 2003), so that there is no difference in this feature between $S$. tabascoensis and S. macrospinosus. The same arrangement of posterior pairs of postanal papillae and phasmids is characteristic of the great majority of cystidicolids.

Whereas Choudhury and Perryman (2003) reported the length of the left spicule of $S$. macrospinosus to be 125 $155 \mu \mathrm{m}$, the same spicule in $S$. tabascoensis was found to be $210-240 \mu \mathrm{m}$. The size of this spicule evidently depends on the body size of the male, as previously observed, e.g., by Moravec (1979) in Spinitectus inermis (Zeder, 1800); the males of $S$. macrospinosus were 5.5-8 mm long, whereas those of $S$. tabascoensis measured 7-12 $\mathrm{mm}$.

A characteristic feature of $S$. macrospinosus should be the presence of a "terminal heart-shaped mucron set off from body by narrow constriction" on the female tail tip, whereas a "knob-like mucron" was reported for S. tabascoensis. However, in this case, the shape of mucron can hardly be considered a specific feature, because in cystidicolids it may exhibit a considerable degree of intraspecific variability, often depending on the mode of fixation.

It is apparent from the above discussion that there are no substantial morphometrical differences between S. macrospinosus and S. tabascoensis. Moreover, the type host (Ictalurus furcatus) of the latter species is distributed from Mexico and northern Guatemala to major rivers of the Mississippi, Missouri and Ohio basins (Froese and Pauly 2009), from where S. macrospinosus was reported from I. furcatus and I. punctatus; the latter fish host has a similar distribution to that of I. furcatus, being spread in central drainages of the USA to southern Canada and northern Mexico (Froese and Pauly 2009). Therefore, S. macrospinosus should be considered a junior synonym of S. tabascoensis. Consequently, the geographical distribution of this parasite seems to follow that of its definitive hosts, Ictalurus spp. (see above).

Juvenile specimens (probably fourth-stage larvae) of S. tabascoensis from ariid catfishes C. aguadulce and P. nelsoni of the present material were $6.34-6.94 \mathrm{~mm}$ long and their species identification was mainly based on their markedly long cuticular spines (maximum length $27 \mu \mathrm{m})$; in contrast to adults from I. furcatus, the excretory pore of specimens from $P$. nelsoni was found to be located between the 7 th and 8 th cuticular rings (instead of 6th and 7th rings in adults). Apparently, S. tabascoensis is unable to attain maturity in these ariid catfishes, which thus cannot become definitive hosts of this parasite. The same probably concerns Noturus flavus and Hiodon alosoides as observed by Choudhury and Perryman (2003) in southern Canada. All these fishes serve only as facultative paratenic (metaparatenic) hosts for this nematode parasite (Odening 1976).

\section{Spinitectus osorioi Choudhury et Pérez-Ponce de León, 2001}

Figs. 3, 4

Brief morphometrical data on specimens from E. mexicanus: First ring with 29-36 spines (Figs. 3E, 4B); largest spines in 5th-13th rows. Length ratio of muscular/ glandular portions of oesophagus 1:2.3-5.3. Nerve ring between $3 \mathrm{rd}$ and 4 th rings of spines, excretory pore between 6th and 7th rings (Fig. 3A).

Male (5 specimens): Length of body 3.73-4.72 mm; maximum width 95-109. First ring of spines situated 57-75 from anterior extremity, consists of 29-35 spines 6 long; maximum length of spines in more posterior (6th9th) rings 15-18. Length of vestibule including prostom 93-105; prostom 9 long, 15-18 wide. Muscular oesophagus 189-321 long, maximum width 15-18; glandular oesophagus $0.84-1.01 \mathrm{~mm}$ long, maximum width 48-51; ratio 1:2.9-5.3. Length of vestibule and entire oesophagus represents $27-33 \%$ of whole body length. Large (left) spicule 420-480 long; length of shaft 195-240 (44-51\% of spicule length) (Figs. 3G, 4D). Small (right) spicule 111135 long (Fig. 3H). Length ratio of spicules 1:3.6-3.9. Tail 147-165 long, with minute terminal cuticular spike.

Female (2 gravid specimens with mature eggs; measurements of 1 juvenile female undergoing last moult, already containing small number of immature eggs, in parentheses): Length of body 6.35-7.94 (4.76) mm; maximum width $122-150$ (109). First ring of spines 87-96 (90) from anterior extremity, consists of 32-36 spines 6 (6) long; maximum length of spines in 7th-13th rings 18 21 (18); (old, four-stage larval cuticle of juvenile specimen with distinctly smaller and more numerous spines per ring). Length of vestibule including prostom 93-105 (99); prostom 9-12 (12) long, 15-18 (18) wide. Muscular oesophagus 291-513 (330) long, maximum width 15-18 (15); glandular oesophagus $0.98-1.19(0.85) \mathrm{mm}$ long, maxi- 

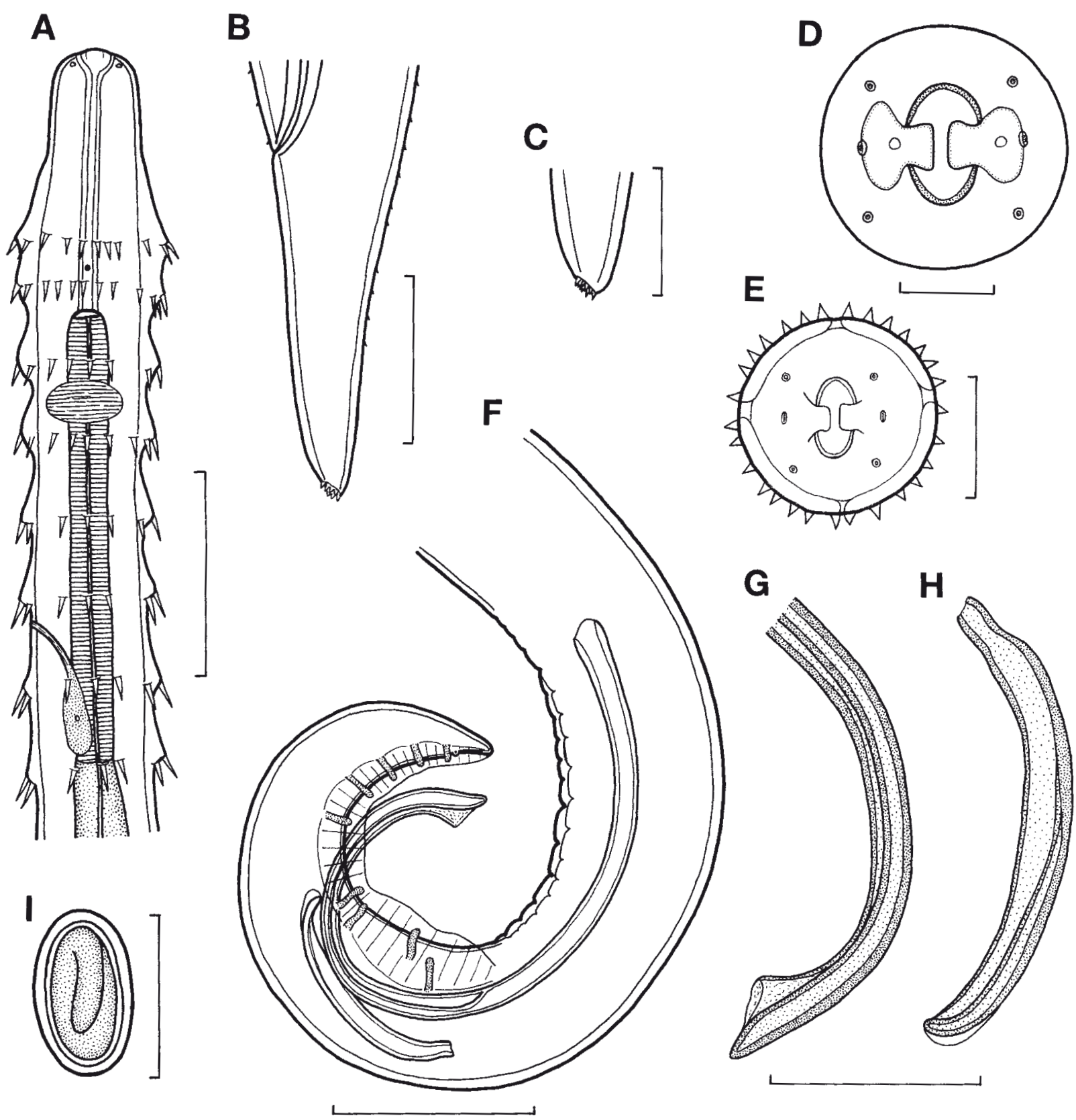

Fig. 3. Spinitectus osorioi Choudhury et Pérez-Ponce de León, 2001 from Eugerres mexicanus. A - anterior end of gravid female, lateral view; B - tail of female, lateral view; $\mathbf{C}$ - tip of female tail, lateral view; $\mathbf{D}$ - mouth, apical view; $\mathbf{E}$ - cephalic end, apical view; $\mathbf{F}$ - posterior end of male, lateral view; $\mathbf{G}$ - distal end of large (left) spicule, lateral view; $\mathbf{H}$ - small (right) spicule, lateral view; I - fully developed egg. Scale bars: A, F $=100 \mu \mathrm{m} ; \mathrm{B}, \mathrm{G}, \mathrm{H}=50 \mu \mathrm{m} ; \mathrm{C}, \mathrm{I}=30 \mu \mathrm{m} ; \mathrm{D}=10 \mu \mathrm{m} ; \mathrm{E}=20 \mu \mathrm{m}$.

mum width 33-42 (45); ratio 1:2.3-3.4 (1:2.6). Length of vestibule and entire oesophagus represents $21-23(27) \%$ of body length. Nerve ring and excretory pore 156-174 (159) and 246-291 (246), respectively, from anterior extremity. Deirids 93-108 (-) from anterior body end. Vulva $3.17-3.69$ (2.72) $\mathrm{mm}$ from anterior extremity (at 46-50 (57)\% of body length); vulval lips not elevated. Fully-developed eggs 30-33 × 21 (-). Tail conical, 99-117 (93) long, with terminal, somewhat ventrally shifted mucron bearing numerous minute processes (Figs. 3B, C, 4E).

Hosts: Gulf silverside, Atherinella alvarezi (Díaz-Pardo) (Atherinopsidae, Atheriniformes) (body length 6-9 $\mathrm{cm}$ ) and Mexican mojarra, Eugerres mexicanus (Steindachner) (Gerreidae, Perciformes) (body length 26-27 cm). Previously reported from slender silverside, Chirostoma attenuatum Meek (type host), pike silverside, C. estor Jordan, and bigeye silverside, C. grandocule (Steindachner) (Choudhury and 

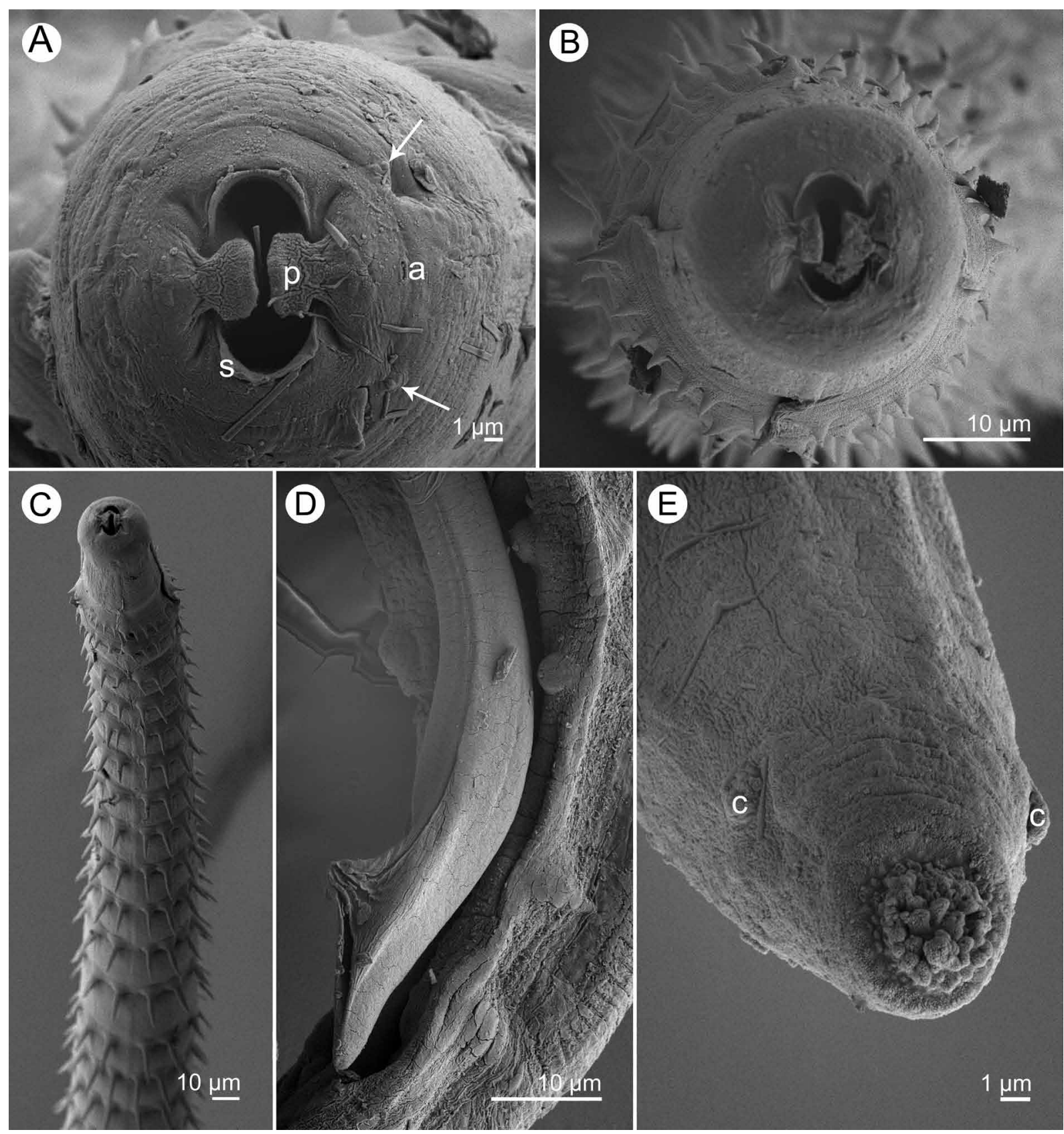

Fig. 4. Spinitectus osorioi Choudhury et Pérez-Ponce de León, 2001 from Eugerres mexicanus, scanning electron micrographs. A - cephalic end, apical view (arrows indicate submedian cephalic papillae); B - anterior end, apical view (focused to first ring of spines); $\mathbf{C}$ - anterior end of body, dorsal view; $\mathbf{D}$ - distal end of large (left) spicule; $\mathbf{E}$ - tail tip of female with distinct terminal mucron and phasmids, subapical view. Abbreviations: a - amphid; c - phasmid; $\mathrm{p}$ - pseudolabium; s - sublabium.

Pérez-Ponce de León 2001, Lira-Guerrero et al. 2008), and A. alvarezi (see Caspeta-Mandujano 2005, Moravec et al. 2010) (all Atherinopsidae, Atheriniformes).

Site of infection: Intestine (A. alvarezi) and stomach (E. mexicanus).

L o c a lity: Lacantún River (Usumacinta R. basin), Chiapas, southern Mexico (collected December 2004 and November 2007). Previously also reported from Lakes Pátzcuaro and Zirahuén in Michoacán, central Mexico (Choudhury and Pérez-Ponce de León 2001, Lira-Guerrero 2008) and Michol
River near Palenque, Chiapas, southern Mexico (CaspetaMandujano 2005, Moravec et al. 2010).

Prevalence and intensity: Atherinella alvarezi: 2 fish infected $/ 5$ fish examined; 1 nematode per fish. E. mexicanus: $2 / 4 ; 7$ and 20 specimens.

Deposition of voucher specimens: Helminthological Collection of the Instituto de Biología, UNAM, Mexico City (Cat. No. 6890); Helminthological Collection of the Institute of Parasitology, Biology Centre of the ASCR (Cat. No. N-802). 
Comments. The general morphology of specimens of the present material, both from A. alvarezi and E. mexicanus, is, more or less, in agreement with the original description of Spinitectus osorioi from Chirostoma spp. given by Choudhury and Pérez-Ponce de León (2001) and the redescription of this species from $A$. alvarezi provided recently by Moravec et al. (2010). Similarly to specimens from $A$. alvarezi reported by the latter authors, those from E. mexicanus exhibit mostly somewhat shorter spicules and smaller eggs as compared to those from Chirostoma spp., but these differences are negligible and can be considered to be within the intraspecific variability of $S$. osorioi.

Spinitectus osorioi has so far been known as a specific intestinal parasite of atherinopsid fishes Chirostoma attenuatum, C. estor and C. grandocule in Lakes Pátzcuaro and Zirahuén in Michoacán (Choudhury and Pérez-Ponce de León 2001, Lira-Guerrero et al. 2008) and from Atherinella alvarezi from the Michol River near Palenque in Chiapas (Caspeta-Mandujano 2005, Moravec et al. 2010). The present finding of this species in E. mexicanus (a new host record) is remarkable in that this host is a fish belonging to the perciform family Gerreidae, whereas all other hosts to the atheriniform family Atherinopsidae. Moreover, all specimens of $S$. osorioi in E. mexicanus were found in the stomach, whereas in all other host species this parasite always occurred in the intestine. Therefore, it can be deduced that $E$. mexicanus is not the true definitive host of $S$. osorioi, but only its facultative postcyclic host (see Odening 1976) acquiring infection with adult worms by feeding on the true fish definitive hosts available in the locality, probably small $A$. alvarezi.

Acknowledgements. We thank Guillermina Cabañas-Carranza, Jessica Pérez-Sánchez, Jesús Montoya-Mendoza and Aliberth Mora-Bonilla, students of the Institute of Biology, Universidad Nacional Autónoma de México (UNAM), México City, for their help with collecting and examining fishes in Chiapas. Thanks are also due to the staff of the Laboratory of Electron Microscopy, Institute of Parasitology, BC ASCR, České Budějovice, for their technical assistance, and to Irena Husáková, a technician of the same Institute, for her help with illustrations. This study was supported by the projects PAPIIT No. IN 229807 and PAPIME No. PE 209106 of the Universidad Nacional Autónoma de México, Dirección General del Asuntos del Personal Académico, DGAPA, and partly by research projects of the Institute of Parasitology, BC ASCR (Z60220518 and LC522).

\section{REFERENCES}

Caspeta-Mandujano J.M. 2005: Nematode Parasites of Freshwater Fish in Mexico: Key to Species, Descriptions and Distribution. Facultad de Ciencias Biológicas, Universidad Autónoma del Estado de Morelos, Cuernavaca, México, 175 pp.

Caspeta-Mandujano J.M., Cabañas-Carranza G., SalgadoMaldonado G. 2007: Spinitectus mariaisabelae n. sp. (Nematoda: Cystidicolidae) from the intestine of the freshwater fish Profundulus punctatus (Cyprinodontiformes) in Mexico. Helminthologia 44: 103-106.

Choudhury A., Pérez-Ponce de León G. 2001: Spinitectus osorioi n. sp. (Nematoda: Cystidicolidae) from Chirostoma spp. (Osteichthyes: Atherinidae) in Lake Pátzcuaro, Michoacán, México. J. Parasitol. 87: 648-655.

Choudhury A., Perryman B.J. 2003: Spinitectus macrospinosus n. sp. (Nematoda: Cystidicolidae) from the channel catfish Ictalurus punctatus in southern Manitoba and its distribution in other Ictalurus spp. J. Parasitol. 89: 782-791.

Froese R., Pauly D. (Eds.) 2009: FishBase. World Wide Web electronic publication. www.fishbase.org, 8/2009.

Hoffnagle T.L., Cole R.A., Shoop W.L. 1990: Gastrointestinal parasites of the blue catfish (Ictalurus furcatus) in Kentucky Lake, Tennessee. J. Helminthol. Soc. Wash. 57: 40-43.

JiLEK R., CRITES J.L. 1982: Comparative morphology of the North American species of Spinitectus (Nematoda: Spirurida) analyzed by scanning electron microscopy. Trans. Am. Microsc. Soc. 101: 126-134.

Ko R.C. 1986: A Preliminary Review of the Genus Ascarophis van Beneden, 1871 (Nematoda: Cystidicolidae) of the Gastrointestinal Tract of Fishes. Occasional Publications, Department of Zoology, University of Hong Kong, 54 pp.
Lira-Guerrero G., García-Prieto L., Pérez-Ponce de León G. 2008: Helminth parasites of atherinopsid freshwater fishes (Osteichthyes: Atheriniformes) from central Mexico. Rev. Mex. Biodiv. 70: 325-331.

Moravec F. 1979: Redescription of the nematode Spinitectus inermis parasitic in eels, Anguilla anguilla, of Europe. Acta Soc. Zool. Bohemoslov. 43: 35-42.

Moravec F. 1996: Some new data on the morphology of Spinitectus inermis (Nematoda: Cystidicolidae), a rare parasite of eels, as revealed by SEM. Parasite 3: 169-174.

Moravec F. 2007: Some aspects of the taxonomy and biology of adult spirurine nematodes parasitic in fishes: a review. Folia Parasitol. 54: 239-257.

Moravec F., García-Magaña L., Salgado-Maldonado G. 2002: Spinitectus tabascoensis sp. nov. (Nematoda, Cystidicolidae) from Ictalurus furcatus (Pisces) in southeastern Mexico. Acta Parasitol. 47: 224-227.

Moravec F., Klimpel S. 2007: New data on the morphology of Spinitectus oviflagellis Fourment, 1884 (Nematoda: Cystidicolidae) from the pyloric caeca of Macrourus berglax (Macrouridae) in the eastern Greenland Sea. Syst. Parasitol. 67: 43-50.

Moravec F., Salgado-Maldonado G., Caspeta-Mandujano J.M. 2010: Observations on Spinitectus osorioi (Nematoda: Cystidicolidae) in the Mexican endemic fish Atherinella alvarezi (Atherinidae) from the Atlantic river drainage system in Chiapas, southern Mexico. Mem. Inst. Oswaldo Cruz (In press.)

Odening K. 1976: Conception and terminology of hosts in parasitology. Adv. Parasitol. 14: 1-93. 